2. HISTORIA DE LOS DOGMAS JURÍDICOS 

Revista de Estudios Histórico-Jurídicos [Sección Historia de los Dogmas Jurídicos]

XXXI (Valparaíso, Chile, 2009)

[pp. 171 - 195]

\title{
LAS FUENTES DE LAS NORMAS SOBRE INTERPRETACIÓN DE LAS LEYES DEL "DIGESTE DES LOIS CIVILES" (“CODE CIVIL”) DE LA LUISIANA (1808/1825)
}

["The Sources of the Rules Regarding the Interpretation of Laws of "Digeste Des Lois Civiles" ("Code Civil”) de la Luisiana (1808/1825)"”]

\author{
Alejandro Guzmán Brito* \\ Pontificia Universidad Católica de Valparaíso
}

\begin{abstract}
RESUMEN
En este artículo se examinan las fuentes usadas por los autores del primer código civil promulgado en América, concretamente en la Luisiana, bajo el nombre de Digeste des lois civiles, en 1808, para componer sus normas sobre interpretación de las leyes. La conclusión es que tales fuentes son las pertinentes normas del Project de Code Civil de 1800, antecedentes del Code Civil de 1804, ciertos pasaje de los Commentaries on the Laws of England de William Blackstone y una nota a esta obra de su editor Edward Cristian.

Palabras clave: Digeste des lois civiles - Project de Code Civil de 1800 - William Blackstone - Edward Christian - Interpretación de las leyes.
\end{abstract}

\begin{abstract}
In this article we analise the sources used by the authors of the first civil code enacted in America, in Luisiana to be precise, under the name of Digeste des lois civiles, in 1808 , to draft their rules regarding the interpretation of the law. We concluded that those sources are the pertinent norms of the Project de Code Civil of 1800, prior to the Code Civil of 1804, certain passages of the [Commentaries on the Laws of England] by William Blackstone and a note to this work from its editor, Edward Cristian.

Keywords: Digeste des lois civiles Project de Code Civil of 1800 - William Blackstone - Edwards Christian - Interpretation of the law.
\end{abstract}

* Catedrático de Derecho romano. Dirección postal: Pontificia Universidad Católica de Valparaíso, Facultad de Derecho, Avenida Brasil 2950, Valparaíso, Chile. Correo electrónico: aguzman@ucv.cl 


\section{INTRODUCCIÓN ${ }^{1}$}

1. El territorio de la cuenca del Mississippi, llamado Luisiana, descubierto por los españoles hacia 1542, de pertenecer alternativamente a España y Francia, terminó por integrarse en los Estados Unidos de América a fines de 1803, merced a su compra por ese país a la Francia napoleónica. Pero no fue organizado de inmediato como un Estado, sino como un distrito denominado "Luisiana y territorio de Orleans", con un Consejo Legislativo, dotado de competencia para intervenir en las leyes vigentes, y un gobernador con derecho a veto. Sólo en 1812 se creó el Estado de Luisiana.

Una vez integrada la Luisiana en la Unión, se suscitó el problema de decidir por cuál sistema jurídico habría de regirse en el futuro. Mientras las autoridades estatales, encabezadas por el gobernador, deseaban introducir la "Common Law", los notables del territorio querían mantenerse bajo el imperio del "Derecho civil" (“Civil Law" o "Droit Civil”), representado por las leyes castellanas, a las cuales estaban habituados desde 1769. Temían, en efecto, la sujeción a un Derecho de jueces, que era y es lo característico del anglosajón. En 1806, el Consejo Legislativo de la Luisiana aprobó una ley que confirmaba la vigencia de los cuerpos legales castellanos, la cual, empero, fue vetada por el gobernador; ante ello, el Consejo emitió un manifiesto, donde, entre otras cosas, decía: "[...] in short, the wisdom of the civil law is recognized by all Europe; and this law is the one which nineteen-twentieths of the population of Louisiana know and are accustomed to from childhood, of which law they would not see themselves deprived without falling into despair [...]. There is a secret intention of throwing us, despite ourselves, into the frightful chaos of the common law?"2. La solución final vino dada por el designio de formar un nuevo cuerpo legal, es decir, un código civil, para lo cual la Legislatura del territorio, mediante resolución de 7 de junio de 1806, designó a los juristas

${ }^{1}$ Sobre el proceso de formación de las codificaciones luisianas de 1808 y 1825: Tullis, Robert Lee, The Louisiana Civil Law in the Light of its Origin and Development, en University of Toronto Law Journal 2 (1937-1938), pp. 289-318; STONE, Ferdinand, The Civil Code of 1808 for the Territory of Orleans, en Tulane Law Review 33 (diciembre de 1958) 1, pp. 1-6; HooD, John jr., The History and Development of the Louisiana Civil Code, en Tulane Law Review 33 (diciembre de 1958) 1, pp. 7-20; HooD, John jr., Symposium: Louisiana and the Civil Law. A Crossroad in Louisiana History, en Louisiana Law Review 22 (1961-1962), pp. 709-726; Lifsic, Ricardo, Historia del Código Civil de Louisiana antecedente del Código Civil argentino, en Revista del Instituto de Historia del Derecho 12 (Buenos Aires, 1961), pp. 164-172; Kilbourne, Richard, A History of the Louisiana Civil Code: the Formative Years. 1803-1839 (Baton Rouge, Louisiana State University Press, 1987). Mirada en compendio: HuberT, León jr., Louisiane, en Travaux de la Semaine Internationale de Droit. L'influence du Code Civil dans le monde (Paris, Pedone, 1954), pp. 778-783; LeVASSeur, Alain - Herman, Shael, Louisiane, en Travaux de l'Association Henri Capitant, XLIV: La circulation du modèle juridique français (Paris, Litec, 1993), pp. 649-652.

${ }^{2}$ Cit. por Hood (n. 1), pp. 11-12: “[...] en pocas palabras, podemos decir que la sabiduría del Derecho civil es reconocida en toda Europa; y ese Derecho es el que 19 de cada 20 personas conocen en Luisiana y al que están acostumbradas desde la niñez, las cuales no quieren verse privadas del mismo sin caer en la desesperación [...]; ¿ [...] hay una secreta intención de arrojarnos, a pesar nuestro, en el horrible caos de la "Common Law?" 
James Brown y Louis Moreau-Lislet": "[...] to compile and prepare, jointly a Civil Code for the use of this territory"; y dispuso que ambos jurisconsultos "[...] shall make the civil law by which this territory is now governed, the ground work of said code" ${ }^{4}$ El cuerpo resultante fue aprobado el 31 de marzo de 1808 como Digeste des lois civiles actuellement en force dans le territoire d'Orléans, avec les changements et améliorations adaptés à son present système de gouvernement (A Digest of the Civil Laws Now in Force in the Territory of Orleans, with Alterations and Amendments Adopted to its Present System of Government). En su preparación, los comisionados consumieron poco más de un año y ocho meses 5 .

${ }^{3}$ Éste fue, de hecho, el autor del nuevo cuerpo legal. Sobre él: Levasseur, Alain, Moreau Lislet: The Man Behind the Digest of 1808 (Baton Rouge, Claitor, 2088).

${ }^{4}$ El texto del acuerdo en: TUCKer, John, Source Books of Louisiana Law, en Tulane Law Review 6 (1931-1932), p. 281: “[...] para compilar y preparar, conjuntamente, un Código Civil para uso de este territorio. [...] han de poner como fundamento de dicho código el Derecho civil por el cual es gobernado ahora este territorio".

${ }^{5}$ Hacia 1814, el codificador Moreau-Lislet tenía escrito un texto que tituló: Loix de l'État de la Louisiane avec des notes qui réferent aux Loix civiles et Espagnoles qui y ont rapport ("Leyes del Estado de Luisiana con notas que refieren a las leyes civiles y españolas que se les relacionan"), el cual, empero, restó manuscrito y solo ha venido a ser editado en el siglo XX. Véase: A Reprint of Moreau Lislet's Copy of a Digest of the Civil Laws now in Force in the Territory of Orleans (1808) Containing Manuscript References to its Sources and Other Civils Laws on the Same Subjects. The de la Vergne Volume (Baton Rouge, La. Claitor, 1971); y la recensión de Tate, Thomas, A Digest of the Civil Laws Now in Force in the Territory of Orleans (1808), en Loyola Law Review 17 (1970-1971), pp. 781-783. Se trata de un ejemplar del Digeste, en la que cada página impresa viene enfrentada con una en blanco (y que debió de haber sido especialmente preparada para el autor antes de tirarse la edición normal), en la cual MoreauLislet anotó en manuscrito las fuentes "del Derecho civil y español" que guardaban alguna relación con las disposiciones del Digeste. No es, pues, una relación de fuentes de éste, sino una concordancia del mismo con las fuentes civiles y españolas. Seguramente debió de haber sido escrito con la intención de demostrar que, aunque el Digeste en su mayor parte fuera un reflejo textual o casi, del proyecto francés de 1800 o del código francés de 1804, sus normas coincidían sustancialmente con el Derecho romano y el español, de manera de no haberse en realidad transgredido el programa fijado por los legisladores de 1806. En su momento, Moreau-Lislet, pese a la gran admiración que sentía por las Partidas, debió de considerar demasiado ingente la tarea de confeccionar un código con el esparcido y difuso Derecho castellano vigente en Luisiana, y hasta excesiva, visto que se tenía a la mano la moderna codificación de un Derecho muy coincidente con él, como era la francesa, cuyo empleo ahorraría un trabajo prolongado, para el cual propiamente no se disponía de mucho tiempo en el marco de una situación de emergencia. Sobre el "manuscrito La Vergne": DAinow, Joseph, Moreau-Lislet's Notes on Sources of Louisiana Civil Code of 1808, en Lousiana Law Review 19 (1958), pp. 43-51; Franklin, Mitchell, An Important Document in the History of American, Roman and Civil Law: The De la Vergne Manuscript, en Tulane Law Review 33 (diciembre de 1958) 1, pp. 35-42; PASCAL, Robert, A Recent Discovery: A Copy of the Digest of the Civil Laws of 1808 with Marginal Source Reference in Moreau Lislet's Hand, en Louisiana History 7 (1966), pp. 249-251. Existe otra copia del texto de Moreau-Lislet, aunque con diferencias, el llamado "manuscrito Denis", sobre el cual: Darby, Lawrence - McDonald, Thomas, A Recent Discovery: Another Copy of Moreau Lislet's Annotation to the Civil Code of 1808, en Tulane Law Review 47 (junio de 1973) 4, pp. 1210-1212. 
2. Pese, pues, a que se mandó expresamente a los codificadores basarse en el Derecho castellano (al cual la resolución de 1806 aludía al hablar de "Civil Law"), porque era el vigente hasta entonces en la Luisiana, aquéllos recurrieron preferentemente al material ofrecido por el Projet de Code Civil para Francia terminado en el año VIII de la Revolución (1800) y editado al principios del año siguiente, y eventualmente al código de 1804. Las razones específicas y contingentes que tuvieron los codificadores para usar el "Projet de l'an VIII" permanecen un tanto en el misterio. Pero la razón externa de haber recurrido al modelo francés es clara y se resume en el motivo de la "urgencia". La codificación fue impulsada en la Luisiana por la voluntad de oponer un cuerpo compacto de Derecho vernáculo a la "Common Law" extranjera. Pero confeccionar originalmente un cuerpo de Derecho vernáculo, vale decir, que incluyera a los materiales de la legislación castellana (Partidas, Fuero Real y Recopilación de las leyes de Castilla o "Nueva Recopilación") y acaso de la "Coutume de Paris", era más fácil desearlo y aún proponerlo que llevarlo a la práctica en el poco tiempo de que psicológica y tal vez realmente se disponía. Así que, presionados por la urgencia de tener rápidamente terminado un cuerpo legal de "Civil Law" o "Droit Civil" moderno, recurrieron los comisionados al único disponible, que al principio para ellos no pudo ser otro que el "Projet de l'an VIII", aunque en el curso del trabajo llegaron a tener el Code mismo en sus manos ${ }^{7}$. Por lo demás, también consultaron autores franceses como Domat ${ }^{8}$; y de todos modos no dejaron de usar las fuentes

${ }^{6}$ El profesor de origen mexicano, pero que hizo su carrera académica en Nueva Orleans, Rodolfo Batiza, pensaba que las fuentes mayoritariamente influyentes en el Digeste fueron las francesas. Véase: Batiza, Rodolfo, The Louisiana Civil Code of 1808: Its Actual Sources and Present Relevance, en Tulane Law Review 46 (septiembre de 1971) 1, pp. 4-16; El mismo, The Actual Sources of the Louisiana Project of 1823: A General Analytical Survey, en Tulane Law Review 47 (diciembre de 1972) 1, pp. 1-115; El mismo, Sources of the Civil Code of 1808, Facts and Speculation: A Rejoinder, en Tulane Law Review 46 (abril de 1972) 4, pp. 628-652; EL MISMO Origins of Modern Codification of the Civil Law: The French Experience and its Implications for Louisiana Law, en Tulane Law Review 56 (febrero de 1982) 2, pp. 477-601. Por el contrario, PASCAL, Robert, Sources of the Digest of 1808: A Reply to Professor Batiza, en Tulane Law Review 46 (abril de 1972) 4, pp. 603-627 creía que fue el antiguo Derecho castellano el que influyó en ese cuerpo legal. Escéptico en orden a llegar a resultados concluyentes: SwEENEY, Joseph, Tournament of Scholars over the Sources of the Civil Code of 1808, en Tulane Law Review 46 (abril de 1972) 4, pp. 585-602. Hay trabajos más antiguos: PorTer, B. F., Ancient Sources of Louisiana Law, en The Commercial Review of the South and West (New Orleans, 1846), pp. 374-378; Merrick, E. T., The Laws of Louisiana and their Sources, en The American Law Register 29 (enero de 1890) 1, pp. 1-21; DART, Henry, The Sources of the Civil Code of Louisiana: address delivered at the annual meeting of the Louisiana Bar Association, Held at Lake Charles, La., Friday, June 2, 1911 (New Orleans, J. G. Hauser, 1911).

${ }^{7}$ Baudouin, Louis, The Influence of the Code Napoleon, en Tulane Law Review 33 (diciembre de 1958) 1, pp. 21-34.

${ }^{8}$ TuCKer, Thomas, Sources of Louisiana Law of Persons: Blackstone, Domat and the French Codes, en Tulane Law Review 44 (febrero de 1970) 2, pp. 264-295. 
del Derecho castellano ${ }^{9}$ o del romano ${ }^{10}$ ni autores clásicos de la "Common Law" como Blackstone. A nosotros sólo nos interesarán, por cierto, las fuentes usadas para las reglas de interpretación.

El Digeste des lois civiles fue revisado en 1825 y entonces se aprovechó para cambiar su nombre a Code Civil ${ }^{11}$. Como tal, y atendida la temprana promulgación de este cuerpo legal en América, tuvo influencia importante en las futuras codificaciones de los demás países de ese continente ${ }^{12}$.

\section{LAS NORMAS SOBRE INTERPRETACIÓN DEL "DIGESTE DES LOIS CIVILES"}

El Digeste des lois civiles $^{13}$ luisiano de 1808 trata de la materia hermenéutica en el capítulo 4\%: De l'application et de l'interprétation de la loi, del Titre préliminaire, artículos 13 a 22. Su modelo inmediato fue el título 5०: De l'application et de l'interprétation des lois, del Livre préliminaire del Projet de Code Civil del año VIII" ${ }^{14} ;$ sin embargo, los codificadores luisianos insertaron en ese esquema algunos conceptos extraídos de otras fuentes.

1. El código luisiano prescindió de todas las disposiciones del proyecto francés concernientes a los tipos de interpretación, con que éste iniciaba el articulado de su título $5^{\circ}$ (artículos 1 a 4). Antes, sin embargo, en el capítulo 3o después de haber tratado en su artículo 7 (que cambió su número al 8 en la revisión de 1825)

${ }^{9}$ Batiza, Rodolfo, The Influence of Spanish Law in Louisiana, en Tulane Law Review 33 (diciembre de 1958) 1, pp. 29-34; Colvin, Milton, The Influence of the Ancient Laws of Spain on the Jurisprudence of Louisiana, en Tulane Law Review 6 (1931-1932), pp. 83-97; REYNOLDS, C. Russell, Spanish Law Influence in Louisiana, en Hispania 56 (American Association of Teachers of Spanish and Portuguese, Walled Lake, Mi, diciembre de 1973) 4, pp. 1076-1082; CASTÁn VÁzQUEZ, José María, La influencia de la literatura jurídica española en las codificaciones americanas (Madrid, Real Academia de Jurisprudencia y Legislación, 1984), pp. 143-151.

${ }^{10}$ Batiza, Rodolfo, Justinian's Institute and the Louisiana Civil Code of 1808, en Tulane Law Review 69 (junio de 1995) 6, pp. 1639-1648; El mismo, Roman Law in the French and Louisiana Civil Codes: A Comparative Textual Survey, en Tulane Law Review 69 (1995) 6, pp. 1601-1630; SNYDER, David, Ancient Law and modern Eyes, en Tulane Law Review 69 (junio de 1995) 6, pp. 1631 ss.

${ }^{11}$ La descripción literaria de ambos cuerpos legales en: TuCKER, John, Source Books of Louisiana Law, en Tulane Law Review 6 (1931-1932), pp. 280-300.

${ }^{12}$ Un panorama de tal influencia se ve en: KNÜTEL, Rolf, Influences of the Louisiana Civil Code in Latin America, en Tulane Law Review 70 (1996) 5, pp. 1445-1480.

${ }^{13}$ Edición: Digeste des lois civiles, en Compiled Edition of the Civil Code of Louisiana prepared by The Louisiana State Law Institute (Baton Rouge, Louisiana, 1940), III, 1; las normas sobre interpretación, en pp. 8-12.

${ }^{14}$ Aquí usamos la edición que se ve en: FENET, Pierre-Antoine, Recueil complet des travaux préparatoires du Code Civil (Paris, Videcoq, 1836), II; las normas sobre interpretación, en pp. 6-7, que en lo sucesivo no volveremos a citar. Acerca de las fuentes de este proyecto, a su vez, puede verse: GUZMÁN BRITO, Alejandro, Las normas sobre interpretación de las leyes contenidas en el "Projet de Code Civil" de l'an VIII (1800), en LABruna, Luigi (director), Cinquanta anni della Corte Costituzionale della Repubblica Italiana, I: Tradizione romanistica e costituzione (Napoli, Edizioni Scientifiche Italiane, 2006), I, pp. 1.809-1.840. 
sobre la irretroactividad de las leyes, el código luisiano estableció un artículo 8, en imitación del artículo 3 del título $4^{\circ}$ del Livre préliminaire del "Projet de l'an VIII":

"Projet de l'an VIII", tít. 4º, art. 3

"Néanmoins, une loi explicative d'une autre loi précédente règle même le passé, sans préjudice des jugemens en dernier ressort, des transactions et décisions arbitrales passées en force de chose jugée".
Digeste de la loi civil, art. 7

"Néanmoins, une loi explicative, ou déclaratoire d'une autre loi précédente règle même le passé, sans préjudice des jugemens en dernier ressort, des transaction et décisions arbitrales passées en force de chose jugée".

\section{Traducción}

"Sin embargo, una ley explicativa de otra ley precedente regla también el pasado, sin perjuicio de las sentencias en última instancia, de las transacciones y de las decisiones arbitrales pasadas en fuerza de cosa juzgada”.
"Sin embargo, una ley explicativa, o declaratoria de otra ley precedente regla también el pasado, sin perjuicio de las sentencias en última instancia, de las transacciones y de las decisiones arbitrales pasadas en fuerza de cosa juzgada".

Como se ve, el Digeste se limitó a añadir la frase: "ou déclaratoire”, con la que seguramente intentó definir la noción inmediatamente anterior de "loi explicative". Esta norma, empero, fue suprimida en la revisión de 1825 .

2. El artículo 13 luisiano (= título 5º artículo 5 del "Projet de l'an VIII”), el primero de los que integran su capítulo $4^{\circ}$, dijo:

"Projet de l'an VIII", tít. 5, art. 5

"Quand une loi est claire, il ne faut point en éluder la lettre, sous prétexte d'en pénétrer l'esprit;

et dans l'application d'une loi obscure, on doit préférer le sens le plus naturel et celui qui est le moins défectueux dans l'exécution".
Digeste de la loi civil, art. 13

"Quand une loi est claire et sans ambiguïté, il ne faut point en éluder la lettre, sous prétexte d'en pénétrer l'esprit".

\section{Traducción}

"Cuando una ley es clara, no hay que eludir en nada la letra, bajo pretexto de penetrar en el espíritu;

y en la aplicación de una ley obscura, se debe preferir el sentido más natural y aquel que es menos defectuoso en la ejecución".
"Cuando una ley es clara y sin ambigüedad, no hay que eludir en nada la letra, bajo pretexto de penetrar en el espíritu”.

El código luisiano, pues, añadió la expresión "et sans ambiguïtê", tal vez con 
base en Domat, quien constantemente usa la dicotomía "oscuridad-ambigüedad"15; y suprimió el segundo segmento de la disposición francesa "et dans"- "l'exécution”. La razón de haberlo suprimido tal vez se conecte con el hecho de que los artículos siguientes tratan sobre significado de las palabras -acerca de lo cual nada más se dice en el "Projet de l'an VIII", que lo expresado tan en general en este segundo segmento de su artículo 13-, de modo de haber parecido superfluo ese segmento a los codificadores luisianos.

3. A partir de su artículo 14 y hasta el 18, los textos luisiano dejan de corresponderse con los del "Projet de l'an VIII".

a) Los artículos 14 y 15 tratan de los términos de la ley. De hecho, tal tema, como acabamos de anunciar, ni siquiera es objeto de regulación alguna en el mencionado "Projet". Los codificadores luisianos, en cambio, hallaron algo concerniente en los célebres y pronto clásicos Commentaries on the Laws of England (1765-1769), de William Blackstone (1723-1780) ${ }^{16}$. En esta obra, su autor trata de la interpretación de las leyes en la "Introduction": Of the Study, Nature and Extent of the Laws of England ("Introduccción: Del estudio, naturaleza y extensión de las leyes de Inglaterra"), sección 2a: Of the Nature of Laws in General ${ }^{17}$. Para el cotejo, los artículos luisianos han de ser transcritos en su versión inglesa, porque ella debió ser la usada por los codificadores ${ }^{18}$. En nota ofrecemos la versión francesa:

${ }^{15}$ Por ejemplo: Domat, Jean, Les lois civiles dans leur ordre naturel, lib. prel., tít. $1^{\circ}$, sec. 2a, párrafo inicial y 9 (Paris, chez Th. de Hansy, 1735), I, pp. $4-5$ y 7.

${ }^{16}$ BLackstone, William, Commentaries on the Laws of England in four Books ( $8^{\mathrm{a}}$ edición, Oxford, Clarendon Press, 1778). Durante mucho tiempo hubo para mí una suerte de "eslabón perdido" entre los artículos 14 a 18 del Digeste des lois civiles y Pufendorf, De iure nat. et gent., y otros autores anteriores. La conexión conceptual era evidente, pero faltaba la conexión textual. El profesor Antonio Bascuñán Rodríguez, de la Universidad de Chile, descubrió esta última en Blackstone y la expuso en lecciones orales cuyo rumor llegó a mis oídos, ante lo cual, practicados los oportunos cotejos, pude confirmar la intervención del indicado autor inglés, con alguna rectificación concerniente al artículo 17 (véase más abajo, el número 6). Aunque el profesor Bascuñán no ha puesto a la fecha por escrito su descubrimiento, que yo sepa, me place reconocerle su paternidad en nuestro medio; lo cual digo, porque BATIZA, Rodolfo, The Louisiana Civil Code of 1808: Its Actual Sources and Present Relevance, en Tulane Law Review 46 (septiembre de 1971) 1, p. 45, señala la dependencia de los artículos 14, 15, 16 y 17 y 18 del Digeste con respecto a Blackstone (aunque no cuida de señalar que el artículo 17 en realidad depende de su editor y anotador Edward Christian, como veremos en el núnero 6).

${ }^{17}$ Ibíd., pp. 59-62.

${ }^{18}$ La primera traducción al francés de la obra en examen fue como sigue: Commentaires sur les loix angloises, de M. Blackstone. Traduits de l'Anglois par M. D. G sur la quatrième édition d'Oxford (Bruxelles, J. L. de Boubers, 1774-1776), seis volúmenes. Mas, por lo que se dirá a propósito del artículo 17 del Digeste (véase el número 6 siguiente), los codificadores tuvieron en cuenta las notas de Edward Christian al texto de Blackstone, que sólo aparecieron en la edición de entre 1793-1795, cuidada por aquel mismo. En otras palabras, las notas de Christian no pudieron aparecer en la edición francesa de Bruselas. Por cierto, en teoría igual pudieron tenerla a la vista los codificadores; pero no podemos saberlo. 
b) Por lo que atañe al artículo 14, he aquí los textos:

Blackstone, Commentaries

"Words are generally to be understood in their usual and most known signification; not so much regarding the propriety of grammar, as their general and popular use" 19 .
Digest of the Civil Law, art. 14

"The words of a law are generally to be understood in their most known and usual signification, without attending so much to the niceties of grammar rules as to the general and popular use of the words" ${ }^{20}$.

\section{Traducción}

"Las palabras deben ser generalmente entendidas en su usual y más conocida significación; no mirando tanto la propiedad de la gramática, como su uso general y popular”.
"Las palabras de la ley generalmente deben ser entendidas en su más conocida y usual significación, sin atender tanto a los refinamientos de las reglas de la gramática como al uso general y popular de las palabras".

Blackstone, por cierto, no ofreció ninguna originalidad. Por lo demás, inmediatamente de terminado el pasaje antes transcrito que sirvió de fuente al artículo 14 luisiano, aquél invoca expresamente el De iure naturae et gentium de Pufendorf con una cita que corresponde al siguiente pasaje:

\section{Pufendorf, De iure naturae et gentium \\ "De verbis haec est regula: si nulla sit sufficiens coniectura, quae ducat alio,}

verba intelligenda sunt in proprio suo et famoso, ut locuuntur, significatu, quem ipsis imposuit non tam proprietas aut analogia Grammatica, quam popularis usus,.

quem penes arbitrium est, et ius et norma loquendi” ${ }^{21}$.

\section{Blackstone, Commentaries}

"Words are generally to be understood in their usual and most known signification; not so much regarding the propriety of grammar, as their general and popular use".

${ }^{19}$ Blackstone, W., Commentaries, cit. (n. 16), p. 59-60.

${ }^{20}$ Digeste des lois civiles, art. 14: "Les termes d'une loi doivent être généralement entendus dans leur signification la plus connue et la plus usitée, sans s'attacher autant aux raffinemens des règles de la grammaire, qu'à leur acception générale et vulgaire" ("Los términos de una ley deben ser entendidos generalmente en su significación más conocida y usada, si atenerse tanto a los refinamientos de las reglas de la Gramática, cuanto a su acepción general y vulgar”).

${ }^{21}$ Pufendorf, Samuel, De iure naturae et gentium libri octo, lib. V, cap. $12^{\circ}, \$ 3$ (Francofurti et Lipsiae, ex officina Knochio-Eslingeriana, 1759, reimpresión Frankfurt am Main, Minerva, 1967), I, p. 811. 


\section{Traducción}

"Acerca de las palabras, la regla es ésta: si no haya ninguna conjetura suficiente que conduzca a algo distinto,

las palabras deben ser entendidas en su significado propio y, como se dice, famoso, que impuso a las mismas, no tanto la propiedad o la analogía gramaticales, cuanto el uso popular,
"Las palabras de la ley generalmente deben ser entendidas en su más conocida y usual significación, sin atender tanto a los refinamientos de las reglas de la gramática como al uso general y popular de las palabras".

en cuyo poder están la facultad y la norma del hablar".

Pufendorf, por su lado, escribió bajo el influjo directo de Grotius, como se observa merced a la siguiente comparación:

Grotius, De iure belli ac pacis

"Si nulla sit coniectura quae ducat alio, verba intelligenda sunt ex proprietate, non Grammatica quae est ex origine, sed populari ex usu" 22 .
Pufendorf, De iure naturae et gentium

"[...] si nulla sit sufficiens coniectura, quae ducat alio, verba intelligenda sunt in proprio suo et famoso, ut locuuntur, significatu, quem ipsis imposuit non tam proprietas aut analogia Grammatica, quam popularis usus $[\ldots]$.

Traducción

"Si no haya ninguna conjetura que conduzca a algo distinto, las palabras deben ser entendidas según la propiedad, no gramatical, que está en su origen, sino del uso popular".
"[...] si no haya ninguna conjetura suficiente que conduzca a algo distinto, las palabras deben ser entendidas en su significado propio y, como se dice, famoso, que impuso a las mismas, no tanto la propiedad o la analogía gramaticales, cuanto el uso popular $[\ldots]$ ".

Pero el texto de Grotius parece un apretado resumen de unas explicaciones que Francisco Suárez había dado acerca de la inteligencia de las palabras de la ley. Después de distinguir una significación propia natural u originaria de las palabras -como "muerte" que significa la muerte biológica- y una significación propia civil en las mismas -creada por ampliación, igualación o ficción del Derecho, como la "muerte civil"-, añade una tercera: "Quibus addi potest tertia significatio, quae vocari potest usualis, quia est ab usu et consuetudine loquendi, quae magnam vim habere solet in significatione vocum interpretanda, adeo ut in legum expositione proprietati etiam verborum usus praeferendus sit, ut iuris periti cum Bartholi docent

${ }^{22}$ Grotius, Hugo, De iure belli ac pacis libri tres, lib. II, cap. $16^{\circ}, \$ 2$ [ed. B. J. A. De Kanter van Hettinga, Lugduni Batavorum, Brill, 1939, reimp. Aalen, Scientia, 1993, p. 408]. 
in 1. Non dubium, Codice de Legibus, in l. Labeo, ff. De suppelle. lega. \& in 1. 1. ff. De suis \& legit. haered., Panormitanus, in proem. Decretalium, ubi latissime Felinus plurima congerit. Ne vero tot membra multiplicemus, hanc significationem ad duas praecedentes revocamus; nam si usus verbi sit communis totius populi in vulgari modo loquendi, iam illa significatio est facta magis propria magisque naturalis, quam primaeva, quia usus habet vim derogandi institutionem et mutandi impositionem humanam. Si autem usus sit solius iuris, talis significatio sub civili continetur. Regula ergo proposita de priori proprietate est intelligenda, per se loquendo, et nisi circunstantiae ocurrentes, vel alia iura cogant, extensiones vel limitationem facere [...]"23.

Como habrá podido apreciarse, Suárez dice: i) las palabras pueden recibir su significado a partir del uso y costumbre del hablar del pueblo; ii) este significado usual debe ser preferido al propio natural, como lo enseñan los juristas y canonistas, que cita; iii) para evitar multiplicar los conceptos, el significado usual pertenece a los dos precedentes, vale decir, ora al propio natural, si el uso le da cierta significación generalizada en el pueblo, ora al propio civil, si el uso es circunscrito al ámbito del Derecho; iv) por lo cual, el significado usual no es una tercera especie de tal, sino propio; v) se debe estar al significado propio natural si no hay otras circunstancias que obliguen a variarlo, por extensión o restricción. Ahora bien, es cabalmente todo esto lo que compendiosamente expresa Grotius. Él habla de la propiedad de las palabras, y distingue en ella un entendimiento (o significación) gramatical, que está en el origen, y otro proveniente del uso; pero ambos entendimiento son propios; y sienta como regla que las palabras deben ser entendidas según su propiedad, pero no la gramatical, sino la del uso; a menos que algo haya que conduzca a darles un sentido distinto. Aparte la similitud del contenido de ambos discursos, lo que inclina muy decisivamente a dar a Suárez por fuente de Grotius es la idea común a ambos, pero presentada inicialmente por Suárez, de que el significado proveniente del usus loquendi es un significado propio. Los medievales pensaban distinto: el significado proveniente del usus

${ }^{23}$ SuÁrez, Francisco, De legibus ac Deo legislatore lib. VI, cap. 1º, núm. 9 (Conimbricae, Apud Didacum Gomez de Loureyro, 1612; reimpresión Madrid, Instituto de Estudios Políticos, 1967),IV, fol. 626): "A las cuales puede añadirse una tercera significación, que puede llamarse usual, porque proviene del uso y la costumbre del hablar, que suele tener un gran valor en la interpretación del significado de las voces, hasta el punto de que, en la exposición de las leyes, el uso debe ser preferido incluso a la propiedad de las palabras, como lo enseñan los jurisperitos, con Bartolo, a propósito de la ley Non dubium del Código [sc. de Justiniano], tít. De legibus, de la ley Labeo del Digesto, tít. De suppellectibus legatis y en la 1.1 del Digesto, tít. De suis heredibus; el Panormitano en el Proemio de los Decretales, donde Felino [Sandeo] acumula muchas citas. Mas, para no multiplicar las especies [sc. de significaciones], reducimos esta significación [sc. la usual] a las dos precedentes; pues si el uso de la palabra sea común de todo el pueblo en el modo vulgar del hablar, esa significación ya se hace más propia y más natural que la original, porque el uso tiene fuerza de derogar la institución y de cambiar la imposición humana [sc. de los nombres]. Si, empero, el uso sea sólo del Derecho, tal significación se contiene bajo el [sc. significado] civil. Pero la regla propuesta acerca de la primera propiedad [sc. de las palabras = significado natural] debe ser entendida, hablando por sí y a no ser que circunstancias concurrentes y otros Derechos obliguen a hacer extensiones o imitaciones $[\ldots]$ ”. 
loquendi es impropio ${ }^{24}$; sin perjuicio de lo cual puede primar por sobre el propio en determinadas circunstancias. Ahora bien, a menos de suponer que Grotius consideró como propio el significado proveniente del usus loquendi, por impulso original suyo, lo que es improbable, él no tuvo otra fuente para proceder a la identificación que Suárez.

Después de finalizado este estudio genético de ideas, cuando volvemos al artículo 14 del Código de la Luisiana, debemos tener presente que él, por la intermediación epigonal de Blackstone, contiene sustancialmente el canon romano y medieval del communis usus loquendi $i^{25}$, como modo de entender el sentido de las palabras, si bien en un modo totalmente desligado del problema de si la significación proveniente del uso del hablar es impropia o propia, ya que nada dice al respecto la disposición.

4. En lo concerniente al artículo 15 del Código luisiano, el discurso es parecido al que hemos conducido con respecto a su artículo 14. La derivación inmediata también se radica en Blackstone:

\section{Blackstone, Commentaries}

"Again, terms of art, or technical terms, must be taken according to the acceptation of the learned in each art, trade and science" ${ }^{26}$.
Digest of the Civil Law, art. 15

"Terms of arts, or technical terms and phrases, are to be interpreted according to their received meaning and acceptation with the learned in the art, trade or profession" 27 .

Traducción

"Por otra parte, los términos del arte, o términos técnicos, deben ser tomados de acuerdo con la acepción de los peritos en cada arte, oficio y ciencia”.
"Los términos de las artes, o términos y frases técnicos, deben ser interpretados de acuerdo con su sentido y acepción admitidos por los peritos en el arte, oficio o profesión".

${ }^{24}$ Por todos: Caepolla, Bartholomaeus, De verborum et rerum significatione, en Opera (Lugduni, 1578), fol. 469: "propter communem usum loquendi verba impropriantur" ("las palabras se hacen de sentido impropio en razón del uso común del hablar") [cit. por PIANO-MORTARI, Vincenzo, Ricerche sulla teoria dell'interpretazione del Diritto nel secolo XVI, I: Le premesse (Milano, Giuffré, 1956), p. 77 y nota 57]. Véase sobre la materia: SBRICCOLI, Mario, L’interpretazione dello statuto. Contributo allo studio della funzione dei giuristi nell'etá comunale (Milano, Giuffré, 1969), pp.174-190; Piano-Mortari, V., Ricerche, cit. Ibi, pp. 77-78.

${ }^{25}$ Véase: GuZmán Brito, Alejandro, El “communis usus loquendi” en el Derecho romano, en Revista de Estudios Histórico-Jurídicos 21 (Valparaíso, 1999), pp. 37-64 = Bulletino dell'Istituto di Diritto Romano "Vittorio Scialoia", terza serie, 39 (1997 [pero 2004]), pp. 419-444.

${ }^{26}$ Blackstone, W., Commentaries, cit. (n. 16), p. 60.

${ }^{27}$ Digeste des lois civiles, art. 15: "Les termes de l'art ou les expressions et phrases techniques, doivent être interprétés, conformément à la signification et acception qui leur sont données par les personnes versées dans chacun de ces arts, métiers ou professions" "Los términos del arte o las expresiones y frases técnicas, deben ser interpretadas en conformidad con la significación y acepción que les son dadas por las personas versadas en cada una de estas artes, oficios o profesiones”). 

dorf:

Blackstone no cita fuentes. Pero su texto también parece provenir de Pufen-

Pufendorf, De iure naturae et gentium

"Circa vocabula artium propria, quae vulgo vix capit, observandum est, ut illa explicentur secundum definitiones prudentium cuiusque artis" 28 .

\section{Blackstone, Commentaries}

"Again, terms of art, or technical terms, must be taken according to the acceptation of the learned in each art, trade and science".

\section{Traducción}

"Acerca de los vocablos propios de las artes, que el vulgo difícilmente entiende, debe observarse que ellos son explicados según las definiciones de los peritos de cada arte".
"Por otra parte, los términos del arte, o términos técnicos, deben ser tomados de acuerdo con la acepción de los peritos en cada arte, oficio y ciencia”.

\section{Pufendorf, nuevamente, se basó en Grotius:}

Grotius, De iure belli ac pacis

"In artium autem vocabulis, quae populus vix capit, adhibenda erit artis cuiusque prudentium definitio" ${ }^{29}$.
Pufendorf, De iure naturae et gentium

"Circa vocabula artium propria, quae vulgo vix capit, observandum est, ut illa explicentur secundum definitiones prudentium cuiusque artis".

\section{Traducción}

"En los vocablos de las artes, que el pueblo difícilmente entiende, deberá emplearse la definición de los peritos de cada arte".
"Acerca de los vocablos propios de las artes, que el vulgo difícilmente entiende, debe observarse que ellos son explicados según las definiciones de los peritos de cada arte".

Se observará que Blackstone hace sinónimos los terms of art y los technical terms ${ }^{30}$; pero también que esta última expresión no comparece en los textos transcritos de Grotius y Pufendorf. Sin embargo, Grotius, como vimos, cita una frase de Agustín de Hipona, que alude a las denominaciones que imponen los "técnicos ("technici”); y ello pudo influir en Pufendorf, quien, en una nota, sienta cierta regla (que no nos interesa), presentada así: "Modo is, qui loquitur, et

${ }^{28}$ Pufendorf, S., De iure nat. et gent, lib. V, cap. $12^{\circ}, \$ 4$ [ed. cit. n. 21), I, p. 813].

${ }^{29}$ Grotius, H., De iure belli ac pacis, lib. II, cap. 16o, $\$ 3$ [ed. cit. (n. 22), p. 409). No en la edición de 1625, pero sí en aquella de 1642 [véase la ed. cit. (n. 22), p. 409 n. 5], Grotius cita a Augustinus, Principia rhetorices 9: "Ut multa nova tam a technicis et mathematicis quam a philosophis cognominantur, accipere debemus non tam solito usu consuetudinis, quam pro conditione praecepti" ("Como hay muchas cosas nuevas que son denominadas tanto por los técnicos y matemáticos como por los filósofos, debemos entenderlas no tanto por el habitual uso de la costumbre cuanto por la índole de la enseñanza”).

${ }^{30}$ Recuérdese que la palabra latina ars traduce la griega techné. 
artis et vocabulorum eius technicorum non penitus fuerit ignarus, tunc [...]"31. Así que seguramente fue con base en Pufendorf que Blackstone formó la expresión "tecnical terms".

5. El texto del artículo 16 del Código luisiano también fue derivado de Blackstone, como se ve a continuación:

\section{Blackstone, Commentaries}

"If words happen to be still dubious, we may establish their meaning from the context; with which it may be of singular use to compare a word, or a sentence, whenever they are ambiguous, equivocal, or intricate"32.
Digest of the Civil Law, art. 16

"Where the words of a law are dubious, their meaning may be sought by examining the context, with which the ambiguous words, phrases and sentences may be compared, in order to ascertain their true meaning" 33 .

Traducción

"Si las palabras aún resultan ser dudosas, podemos establecer su sentido por el contexto; con el cual puede ser de singular utilidad comparar una palabra o una oración, siempre que son ambiguas, equívocas o intrincadas".
"Cuando las palabras de la ley son dudosas, su sentido puede ser indagado examinando el contexto, con el cual las palabras, frases $\mathrm{u}$ oraciones ambiguas pueden ser comparadas, en orden a descubrir su verdadero sentido".

Por cierto, Blackstone se basó en el acervo de la tradición para escribir este pasaje. Los juristas del ius commune recurrían al canon referido en él bajo el nombre de interpretatio ex antecedentibus et consequentibus, consistente en dar a una palabra o frase el sentido que les conviene según el de las partes que las preceden o siguen y es congruente con él ${ }^{34}$. Sin embargo, el uso del término contextus para designarlo es más bien raro entre los juristas. De acuerdo con una noticia de Christian Wolf (1679-1754), ese término era propio de los teólogos, que hablaban, pues, de interpretatio ex contextu. Con ocasión de sentar esta regla: "Si quae obscure dicuntur, in antecedentibus vel consequentibus, vel alio loco et occasione sine obscuritate dicta

${ }^{31}$ Pufendorf, S., De iure nat. et gent, lib. V, cap. 12o, $\$ 4$ [ed. cit. (n. 21), I, p. 812 nota 1]: "Si el que habla no fuera completamente ignorante del arte y de sus vocablos técnicos, entonces $[\ldots]$ ”.

${ }^{32}$ Blackstone, W., Commentaries, cit. (n. 16), p. 60.

${ }^{33}$ Digeste des lois civiles, art. 16: "Quand les expressions d'une loi sont douteuses, on peut en rechercher la signification, en examinant et comparant les termes ou phrases ambiguës avec les autres parties de la loi, afin de déterminer leurs véritable sens" ("Cuando las expresiones de una ley son dudosas, se puede buscar la significación examinando y comparando los términos o frases ambiguos con las otras partes de la ley, a fin de determinar su verdadero sentido").

${ }^{34}$ Así, por ejemplo, y por todos: FederICIS, Stephanus de, De interpretatione legum, $1^{\mathrm{a}}$ parte, núm.120: en Tractatus universi iuris (Venetiis, 1634), fol. 213": "Sed notandum est quod verba legis restringuntur tripliciter. Primo, per aliam legem [...]. Secundo per antecedentia et consequentia ipsius legis [...]" ("Pero debe ser notado que las palabras de la ley se restringen de tres maneras. Primero, por otra ley [...]. Segundo, por los antecedentes y consecuentes de la misma ley $[\ldots]^{\text {“. }}$ 
sunt, ea, quae obscure dicuntur, ita interpretanda sunt, ut cum verborum perspicuorum significatione conveniant" 35 , Wolf añade, en efecto, el siguiente comentario: "[...] Theologi dicunt sensum 'erui ex contextu', si eorum, quae obscurius dicta sunt sensus investigatur ex collatione cum antececedentibus et consequentibus: ast 'ex locis parallelis', si quae in uno loco obscurius dicta videntur, explicantur per ea, quae alio in loco conspicua de eadem materia dicuntur" 36.

Blackstone pudo redactar por sí mismo el texto en examen, para recoger doctrina común ${ }^{37}$.

${ }^{35}$ Wolf, Christian, Ius naturae método scientifica pertractatum, $6^{\circ}$ parte, cap. $3^{\circ}, \$ 487$ (Halae Magdebvrgicae, in Officina Libraria Rengeriana, 1746), p. 347 (reimpresión en Wolf, Christian, Gesammelte Werke, Herausgegeben und Bearbeitet von L. École (y otros), II. Abteilung: Lateinische Schriften, Band 22: Jus naturae, Herausgegeben und Bearbeitet por Marcel Thomann, Hildesheim, Georg Olms Verlagsbuchhandlung, 1968): "Si las cosas que se dicen obscuramente, en los [sc. lugares] que anteceden o prosiguen o en otro lugar y ocasión fueron dichas sin obscuridad, aquellas que se dicen obscuramente deben ser interpretadas de modo que convengan con la significación de las palabras perspicuas".

${ }^{36}$ Ibíd., $\$ 487:$ ” [...] Los teólogos dicen que 'el sentido se extrae del contexto', si el sentido de aquellas cosas que se han dicho obscuramente es investigado por la comparación con las que anteceden y prosiguen: pero [sc. dicen que el sentido se extrae] de los 'lugares paralelos', si las cosas dichas en un lugar parecen más obscuras, se explican por aquellas que se dicen perspicuamente acerca de la misma materia en otro lugar". Cfr. ForSTER, Valentin Wilhelm (1574-1620), Interpres sive de interpretatione iuris libri duo, lib. II, cap. 3º, núm. 21 (Witerbergae, Sumpt. C. Berger, Typis Meisnerianis, 1613), p. 333 "Constat enim inter Theologos etiam, in sacra quoque scriptura, generales locos ex specialioribus et certioribus interpretandos esse" ("Pues es constante también entre los teólogos que asimismo en la Sagrada Escritura los lugares generales deben ser interpretados por los más especiales y ciertos”). Pero también en Lógica solía usarse el término, como se ve en el filósofo y lógico (pero también teólogo) alemán Bartholomaeus Keckermann (1572-1608), Systema Logicae (5a edición, Hanoviae, 1611), lib. II, sectio posterior, cap. $1^{\circ}$, p. 373: "Contextus series accurate est perpendenda et ex antecedentium et consequentium nexus interpretatio facienda" ("El encadenamiento del contexto debe ser ponderado cuidadosamente y la interpretación debe ser operada por el nexo de los que anteceden y de los que prosiguen" (citado por DANNEBERG, Lutz, Logik und Hermeneutik im 17. Jahrhundert, en SCHRÖDER, Jan, Theorie der Interpretation vom Humanismus bis zur Romantik. Rechtswisenschaft, Philosophie, Theologie (Stuttgart, Steiner, 2001), p. 90 y nota 61.

${ }^{37}$ Cfr. Pufendorf, S., De iure nat. et gent, lib. V, cap. $12^{\circ}$, $\$ 9$ [ed. cit. (n. 21), I, p. 820]: "Magnam quoque ad interpretationem obscurorum adfert lucem, si haec cum aliis componantur, quae affinitatem quandam cum iisdem habent; puta cum illis locis, ubi idem de simili agit materia, aut cum antecedentibus et consequentibus. Cum enim in dubio voluntas credatur sibi fuisse consentiens, igitur ubi quis uno in loco clare mentem suam circa rem quampiam expressit alio quoque loco ac tempore sibi constare praesumitur, nisi expresse mutatio adpareat" "También arroja una gran luz para la interpretación de las cosas obscuras, si éstas se reúnen con otras con las cuales las mismas tienen cierta afinidad; por ejemplo, con aquellos pasajes donde se trata lo mismo de una materia similar, o con lo que antecede y prosigue. Pues, como en la duda se crea que la voluntad ha consentido consigo, cuando alguien, por lo tanto, de alguna manera expresó en un lugar claramente su mente acerca de un asunto, se presume también constar en otro lugar o tiempo, a no ser que aparezca expresamente un cambio"). La segunda parte del pasaje está muy mal redactada; pero en ella su autor quiso decir que como en la duda se considera que cada uno está de acuerdo consigo mismo, si en un lugar se expresó claramente y oscuramente en otro, se presume haber expresado lo mismo en ambos, y que, por lo tanto, el pasaje oscuro debe interpretarse como quedó dicho en el claro. Seguramente la escasa nitidez que ofrece este texto fue la causa de que Blackstone se inclinara a no usarlo. 
6. El artículo 17 del Código luisiano no reconoce como fuente a Blackstone, sino al "barrister at Law" y "professor of Law" en la Universidad de Cambridge, Edward Christian (1758-1823), quien dirigió la 12a edición de los Commentaries de Blackstone, publicada entre 1793 y $1795^{38}$. Ahora bien, Christian añadió notas propias al texto original (que después fueron republicadas junto con las de otros anotadores, en las muchas ediciones estadounidenses del siglo XIX y aún en las actuales). En el lugar inmediatamente posterior al texto que originó el artículo 16 del Código luisiano, reproducido precedentemente, Blackstone expone la siguiente regla: "Of the same nature and use is the comparison of a law with other laws, that are made by the same legislator, that have some affinity with the subject, or that expressly relate to the same point" 39 . Christian la anoto con el texto que se transcribe a continuación, el cual fue convertido en el artículo 17 por los codificadores luisianos:

Christian, "Notas" a Blackstone, Commentaries

"It is an established rule of construction that statutes in pari materia, or upon the same subject, must be construed with a reference to each other; that is, that what is clear in one statute, shall be called in aid to explain what is obscure and ambiguous in another" ${ }^{40}$.

\section{Digest of the Civil Law, art. 17}

"Laws in pari material, or upon the same subject matter, must be construed with a reference to each other; what is clear in one statute may be called in aid to explain what is doubtful in another" ${ }^{41}$.

${ }^{38}$ Commentaries on the Laws of England in four Books by Sir William Blackstone, Knt. [...]. The Twelfth Edition, with the Last Corrections of the Autor, and with Notes and Additions by Edward Christian, Esq., Barrister at Law and Professor of the Laws on England in the University of Cambridge (London, Printed by S. Strahan \& W. Woodfall for T. Cadell, 1793-1795), 4 volúmenes.

${ }^{39}$ Blackstone, W., Commentaries, cit. (n. 16), p. 60: "De la misma naturaleza y uso es la comparación de una ley con otras leyes, que han sido hechas por el mismo legislador, que tienen afinidad con el tema, o que expresamente se refieran al mismo punto".

${ }^{40}$ Usamos aquí la $13^{\text {a }}$ edición, que incluye las notas de Christian: Commentaries on the Laws of England in four Books by Sir William Blackstone, Knt. [...]. The Thirteenth Edition, with the Last Corrections of the Autor, and with Notes and Additions by Edward Christian, Esq., Barrister at Law and Professor of the Laws on England in the University of Cambridge (London, Printed by S. Strahan for T. Cadell jun. and W. Davies, 1800), I, p. 60 nota 8. Sobre este personaje: Hoffeimer, Michael, The Common Law of Edward Christian, en The Cambridge Law Journal 53 (Cambridge, UK., 1994) 1, pp. 140-163.

${ }^{41}$ Digeste des lois civiles, art. 17: "Les lois in pari materia ou sur un même sujet, doivent être interprétées suivant le rapport qu'elles ont l'une avec l'autre; ce qui est clair dans une loi, peut servir de base pour expliquer ce qui est douteux dans une autre" ("Las leyes in pari materia, o sobre un mismo tema deben ser interpretadas siguiendo la relación que ellas tienen una con la otra; lo que es claro en una ley puede servir de base para explicar aquello que es dudoso en otra”). 


\section{Traducción}

"Es una regla establecida de interpretación que los estatutos in pari materia, o sobre el mismo tema, deben ser interpretados con una referencia recíproca, esto es, que lo que es claro en un estatuto debe ser invocado en apoyo para explanar lo que es oscuro y ambiguo en otro".
"Las leyes in pari materia, o sobre la misma materia tratada, deben ser interpretadas con una referencia recíproca; lo que es claro en un estatuto debe ser invocado en apoyo para explanar lo que es dudoso en otro".

Christian no dice algo sustancialmente diverso a lo que expresa Blackstone; pero seguramente los codificadores luisianos consideraron más general y comprensiva, y aun más clara, la versión de Christian, y por ello la adoptaron.

La regla del artículo 17 difiere de la del artículo 16 en este punto: mientras la última atañe a la comparación de un texto dado con otros anteriores o posteriores de un mismo conjunto literario (una misma ley), la regla del artículo 17 concierne a la comparación de conjuntos textuales diversos, o sea, concretamente, de leyes diferentes. La regla exige, empero, que las leyes comparadas versen sobre materias iguales ("in pari materia").

La expresión no comparece jamás en otras fuentes ${ }^{42}$. Pero sí el canon de interpretación que contiene el texto de Christian. Los medievales lo denominaban interpretatio per aliam legem ${ }^{43}$; y su consistencia aparece bien descrita en el texto de Christian, pues consiste no en otra cosa que en interpretar lo que hay de obscuro o ambiguo en cierta ley por lo que está clara o unívocamente expresado en otra. La Glossa de Accursio exigía que las leyes comparadas fueran "de eadem materia" "44, lo que podemos considerar equivalente a la exigencia de versar todas "in pari materia".

${ }^{42}$ Vogenauer, Stefan, Die Auslegung von Gesetzen in England und auf del Kontinent (Tübingen, Mohr Siebeck, 2001), I, p. 448 nota 141: "Der Begriff 'in pari materia' findet sich in den Quellen nicht [...]" ("El concepto 'in pari materia' no se encuentra en las fuentes [...]". Pero no es el concepto, sino la expresión la que no se halla ahí; y el mismo autor advierte, enseguida, que la noción está presente en varios autores, que cita. Además, hay que añadir que la expresión no se encuentra en las fuentes, con la excepción de Christian en examen.

${ }_{43}$ Véase el texto citado en la nota 34.

${ }^{44}$ AcCursius, Gl. Incivile a D. De legibus et senatusconsultis, etc., 1. Incivile est [AccursIus, Glossa in Digestum Vetus, en Corpus Glossatorum Juris Civilis (Augustae Taurinorum, ex Officina Erasmiana, 1969), VII, p. 15]: “[...] utrumque totum debet legi si totum de eadem materia loquatur [...], nam plerumque principium per finem corrigitur [...]. Item si plures sint coniuncte leges. Idem est propter eandem rationem" ("[...] uno y otro todo debe ser leído si el todo hable de la misma materia [...], pues frecuentemente el principio [sc. de un texto] es corregido por el fin [sc. del mismo texto] [...]. Lo mismo si sean muchas conjuntamente las leyes. Es lo mismo por la misma razón"). La ley Incivile est (Dig. 1,3,24) reza así: "Incivile est nisi tota lege perspecta una aliqua particula eius proposita indicare vel respondere" ("A no ser que se tenga en perspectiva a toda la ley, es incivil juzgar o dictaminar destacando alguna parte singular de ella"). Como se ve, la glosa Incivile pone su atención en la palabra "tota (lege)"; y quiere entonces decir que cuando un todo legal se compara con otro todo, ambos deben versar sobre la misma materia. La ley Incivile est se refería a una única ley; pero la glosa la extiende al caso de tratarse de varias, pues añade que lo mismo dicho antes debe acaecer cuando cada todo es una ley, vale decir, cuando se comparan leyes distintas. 


\section{Christian pudo redactar su "nota" con base en cualquier fuente.}

7. El artículo 18 es el último de la serie de los no fundados en el "Projet de l'an VIII” y que encuentra su fuente en Blackstone. He aquí los textos:

\section{Blackstone, Commentaries}

"But, lastly, the most universal and effectual way of discovering the true meaning of a law, when the words are dubious, is by considering the reason and spirit of it; or the cause which moved the legislator to enact it" ${ }^{\prime 4}$.

\section{Digest of the Civil Law, art. 18}

"The most universal and effectual way of discovering the true meaning of a law, when its expressions are dubious, is by considering the reason and spirit of it, or the cause which induced the Legislature to enact it" ${ }^{46}$.

\section{Traducción}

"Pero, en fin, la vía más universal y eficaz de descubrir el verdadero sentido de la ley, cuando las palabras son dudosas, es considerando la razón y el espíritu de ella; o la causa que movió a estatuirla al legislador. Por lo cual, cesada esta razón, la ley misma debe igualmente cesar con ella”.

"La más universal y eficaz vía de descubrir el verdadero sentido de una ley, cuando sus expresiones son dudosas, es considerando la razón y el espíritu de ella, o la causa que indujo a estatuirla al legislador".

Blackstone seguramente se fundó, como en los otros casos, en Pufendorf:

Pufendorf, De iure naturae et gentium

"Praecipuam quoque vim heic habet ratio legis, seu causa illa, et respectu, qui ad legem ferendam latorem movit. [...]. Et heic valet tritum illud: cessante ratione legis, cessat ipsa lex" ${ }^{\prime 4}$.

\section{Blackstone, Commentaries}

"But, lastly, the most universal and effectual way of discovering the true meaning of a law, when the words are dubious, is by considering the reason and spirit of it; or the cause which moved the legislator to enact it. For when this reason ceases, the law itself ought likewise to cease with it".

\section{Traducción}

"En esta materia también tiene un valor principal la razón de la ley, o aquella causa y consideración que movió al legislador a dar la ley. [...]. Y en este tema vale aquel frecuente dicho: 'habiendo cesado la razón de la ley, cesa la ley misma”".
"Pero, finalmente, la más universal y eficaz manera de descubrir el verdadero significado de una ley, cuando las palabras son dudosas, es considerar la razón y el espíritu de ella, o la causa que movió al legislador a promulgarla. Por lo cual, cesada esta razón, la ley misma también debe cesar con ella".

${ }^{45}$ Blackstone, W., Commentaries, cit. (n. 16), p. 61.

${ }^{46}$ Digeste des lois civiles, art. 18: "Le moyen le plus universel et le plus efficace pour découvrir le véritable sens d'une loi, lorsque les expressions en sont douteuses, est de considérer la raison et l'esprit de cette loi, ou la cause qui a déterminé la Législature à la rendre" "El medio más universal y más eficaz para descubrir el verdadero sentido de una ley, cuando las expresiondes son dudosas, es considerar la razón y el espíritu de esta ley, o la causa que ha determinado a la Legislatura a darla").

${ }^{47}$ Pufendorf, S., De iure nat. et gent, lib. V, cap. 12º $\$ 10$ [ed. cit. (n. 21), I, p. 821]. 
Tres indicios permiten sostener la derivación. El primero es la definición de "razón de la ley" que da Pufendorf y es repetida en términos similares por Blackstone, como "la causa que movió al legislador a promulgar la ley" ("ratio legis, seu causa illa, et respectu, qui ad legem ferendam latorem movit" - "the reason and spirit of it; or the cause which moved the legislator to enact it"). El segundo es la referencia al aforismo "habiendo cesado la ley, cesa la ley misma" que igualmente aparece en Pufendorf ("cessante ratione legis, cessat ipsa lex") y es repetido por Blackstone en el mismo contexto ("this reason ceases, the law itself ought likewise to cease with it"). El tercero es el ejemplo con que este último ilustra los conceptos expuestos ${ }^{48}$ : existe una ley con una prescripción según la cual los que en una tempestad abandonen la nave, pierdan lo transportado en ésta; y que eso, junto con la nave, pertenezcan a los que permanecieron a bordo. Acaeció que, en medio de cierta tempestad, todos abandonaron la nave menos uno, que, por estar enfermo, permaneció a bordo. Inesperadamente la nave se salvó y llegó a puerto. El que se mantuvo a bordo, invocó la ley y reclamó la propiedad de la nave y su cargamento. Pero es claro que la razón de ley fue estimular con un premio a los viajantes y marinos que, con peligro de su vida, permanecen a bordo para salvar la nave. La conducta de aquel que, en el caso propuesto, no abandonó la nave no se adaptó a esta finalidad de la ley, y, por consiguiente, no se le debe favorecer con su aplicación. Blackstone atribuye el ejemplo a Cicerón o a quien haya sido el autor de la Rhetorica ad Herennium ("a case put by Cicero, or whoever was the autor of the rhetorical treatise inscribed to Herennium") ${ }^{49}$; porque el manual latino de retórica, que se nos ha transmitido bajo el nombre indicado siempre fue atribuido a Cicerón, pero con muchas dudas. El ejemplo, en efecto, aparece en Rhet. ad Herenn. 1,11 y Blackstone ofrece esta cita al pie de página. Sin embargo, lo eligió entre los varios ejemplos expuestos por Pufendorf para ilustrar la regla sentada en el texto precedentemente transcrito y en su mismo lugar, en donde el autor incluso cita textualmente el mismo pasaje de la Rhetorica ad Herennium que expone el ejemplo.

Se observará que ya Blackstone habla de "reason and spirit", en una correcta sinonimia que trasunta la influencia que en ese autor tuvo Domat, autor de tal sinonimia ${ }^{50}$.

En esta materia, pues, el Código luisiano se alejó totalmente del proyecto francés, que en el artículo 5 de su título $5^{\circ}$ había no menos que prohibido recurrir al espíritu, como pretexto para eludir la letra de una ley clara ${ }^{51}$, aunque nada dijo acerca de su uso fuera de tal hipótesis. El Código luisiano, en contra, confiere amplia autorización para el uso de la "reason and spirit".

\footnotetext{
${ }^{48}$ Blackstone, W., Commentaries, cit. (n. 16), p. 61.

${ }^{49}$ Ibíd.

${ }^{50}$ Sobre esto, véase: GUZMÁn BRITo, Alejandro, La doctrina de Jean Domat sobre la interpretación de las leyes, en Revista Chilena de Derecho 31 (Santiago de Chile, 2004) 1, pp. 51-55.

51 "Quand une loi est claire, il ne faut point en éluder la lettre, sous prétexte d'en pénétrer l'esprit; et dans l'application d'une loi obscure, on doit préférer le sens le plus naturel et celui qui est le moins défectueux dans l'exécution".
} 
8. El artículo 19 del código luisiano volvió al modelo del "Projet de l'an VIII". En plena concordancia con el artículo 9 del título 5 del "Projet de l'an VIII”, establecía:

"Projet de l'an VIII", tít. 5, art. 9

"Lorsque, par la crainte de quelque fraude, la loi déclare nuls certains actes, ses dispositions ne peuvent être éludées sur le fondement que l'on aurait rapporté la preuve que ces actes ne sont point frauduleux".
Digeste des lois civiles, art. 19

"Lorsque par la crainte de quelque fraude, la loi déclare nuls certains actes, ses dispositions ne peuvent être éludées sur le fondement que l'on aurait rapporté la preuve que ces actes ne sont point frauduleux".

Traducción

"Cuando, por el temor de algún fraude, la ley declara nulos ciertos actos, sus disposiciones no pueden ser eludidas sobre el fundamento de que se habría aportado la prueba de que estos actos no son en nada fraudulentos".
"Cuando, por el temor de algún fraude, la ley declara nulos ciertos actos, sus disposiciones no pueden ser eludidas sobre el fundamento de que se habría aportado la prueba de que estos actos no son en nada fraudulentos".

Pero en la revisión de 1825 se le agregaron dos cláusulas: i) después de "fraude”, ésta: "ou par quelqu'autre raison de bien public"; y ii) después de "frauduleux", esta otra: "et qu'ils ne sont pas contraires au bien public".

9. Lo semejante ocurre con el artículo 20 luisiano respecto al artículo 10 del título 5º del "Projet de l'an VIII":

"Projet de l'an VIII", tít. 5ª art. 10

"La distinction des lois odieuses et des lois favorables, faite dans l'objet d'étendre ou de restreindre leurs dispositions, est abusive".
Digest de la loi civile, art. 20

"La distinction des lois en lois odieuses et en lois favorables, faite dans la vue d'étendre ou de restreindre leurs dispositions, est abusive".

\section{Traducción}

"La distinción de las leyes odiosas y de leyes favorables, hecha con el objeto de extender o de restringir sus disposiciones, es abusiva".
"La distinción de las leyes en leyes odiosas y leyes favorables, hecha con la mira de extender o de restringir sus disposiciones, es abusiva".

Las leves diferencias en la construcción luisiana no añaden nada conceptual al modelo. En la revisión de 1825, esta norma apareció así: "La distinction des lois en lois odieuses et en lois favorables, faite dans la vue d'étendre ou de restreindre leurs dispositions, ne peut être faite par ceux qui sont chargés de les interpréter". La declaración original de ambos códigos, en orden a ser "abusiva" la distinción de leyes odiosas y favorables era inane. Tal seguramente fue la consideración tenida en vista en 1825 para reemplazar la expresión "est abusive" por una directa pro- 
hibición de aplicarla los juzgadores: "ne peut être faite par ceux qui sont chargés de les intepréter".

10. Por su parte el artículo 21 del Digeste reproducía, con modificaciones, el artículo 11 del título 5० del "Projet de l'an VIII":

"Projet de l'an VIII", tít. 5, art. 11

"Dans les matières civiles, le juge, à défaut de loi précise,

est un ministre d'équité.

La équité est le retour à la loi naturelle,
Digeste des lois civiles, art. 21

"Dans les matières civiles, le juge, à défaut de loi précise,

est obligé de procéder conformément à l'équité;

pour décider suivant l'équité, il faut recourir à la loi naturelle

et à la raison,

ou aux usages reçus, dans le silence de la loi [primitive] <positive $>$ "52.

loi positive".

Traducción

"En las materias civiles, el juez, en defecto de ley precisa,

es un ministro de equidad.

La equidad es el retorno a la ley natural
"En las materias civiles, el juez, en defecto de ley precisa,

está obligado a proceder en conformidad con la equidad;

para decidir siguiendo la equidad, hay que recurrir a la ley natural

y a la razón,

o a los usos recibidos, en el silencio de la ley [primitiva] <positiva>". o a los usos recibidos, en el silencio de la ley positiva”.

Mientras el proyecto francés decía: "loi précise, <el juez> est un ministre d'équitê", en el código luisiano se dijo: "loi précise, <el juez> est obligé de procéder conformément à l'équitê", en una formulación evidentemente más exacta y menos retórica. En seguida el proyecto francés manifestaba: "La équité est le retour à la loi naturelle", mientras que el código luisiano expresó: "pour décider suivant l'équité, il faut recourir à la loi naturelle”, en manera también más rigurosa. Se observará, en todo caso, la mención agregada de "la razón" ("à la loi naturelle et à la rasion"),

\footnotetext{
${ }^{52}$ Sobre esta inepta expresión "primitive", véase cuanto decimos más abajo, al final de este número 10.
} 
seguramente determinada por su mención en el artículo 18. La última cláusula: "ou aux usages reçus dans le silence de la loi positive" es idéntica a la francesa, sólo que en la luisiana se dijo "loi primitive" en vez de "loi positive", como señalaba el "Projet de l'an VIII", lo que debió de ser errata nunca corregida sino hasta la revisión hecha en 1825 .

11. En el Digeste luisiano se omitió el artículo 12 del proyecto francés ${ }^{53}$, conservado en el artículo 4 del Code Civil, concerniente al principio de la inexcusabilidad; pero en aquél se acogió el artículo 13 del "Projet de l'an VIII", con modificaciones, como artículo 22:

"Projet de l'an VIII", tít. 5, art. 13

"Dans les matières criminelles, le juge ne peut, en aucun cas, suppléer à la loi".
Digeste des lois civiles, art. 22

"Dans les matières criminelles, le juge ne peut, en aucun cas, interpréter la loi, de manière à suppléer à rien de ce qui peut $\mathrm{y}$ être omis".

Traducción

"En las materias criminales, el juez no puede, en ningún caso, suplir la ley"
"En las materias criminales, el juez no puede, en ningún caso, interpretar la ley, de manera de suplir en nada aquello que pudo ser omitido".

Se observará que la norma luisiana prohíbe interpretar las leyes de materia criminal (“interpréter la loi”) y que de ello es que deduce la prohibición de suplirlas, mientras que el proyecto francés se limitaba a prohibir directa y únicamente la suplencia. Esta norma fue eliminada en la revisión de 1825, probablemente por considerársela mal localizada en un código civil.

\section{CONCLUSIONES Y ADVERTENCIAS}

De los once artículos del Digeste des lois civiles luisiano, concernientes a la interpretación de la ley, hay seis $(7,13,19,20,21$ y 22) indiscutiblemente fundados en sendas disposiciones del Livre préliminaire del "Projet de l'an VIII" (artículos 2 del tít. 4o; y 5, 9, 10, 11 y 13 de su tít. 5\%). Cuatro de tales artículos $(14,15,16$ y 18) derivan de correspondientes pasajes de los Commentaries de Blackstone; y uno, el artículo 17, de una nota de Edward Christian a la misma obra de Blackstone.

Estas conclusiones son no sólo importantes para la historia del Digeste des lois civiles, más también para el Código Civil de Chile, porque la mayoría de las normas pertinentes a la interpretación contenidas en el Título preliminar de este último se basaron en las reglas del Digeste des lois civiles $^{54}$. La historia textual que

53 "Le juge qui refuse ou qui differe de juger, sous prétexte du silence, de l'obscurité ou de l'insuffisance de la loi, se rend coupable d'abus de pouvoir ou de déni de justice".

${ }^{54}$ Para esto, véase GuZmán BRITO, Alejandro, La reglas del Código Civil de Chile sobre 
aquí hemos desenvuelto, pues, también pertenece a la Historia del Derecho civil chileno. Pero asimismo a la del Derecho civil de varios países de Hispanoamérica que adoptaron como suyo el Código de Chile o se dejaron influir por él en materia de hermenéutica legal. Lo primero vale para los siguientes países que codificaron en los años que se indica: Ecuador (1858); los estados de la Confederación Granadina (futura Colombia) sucesivamente entre 1858 y 1866 y desde 1886, el propio estado unitario de la ya denominada Colombia; El Salvador (1859); Venezuela durante 1862; Nicaragua (desde 1867 a 1904); Honduras una vez entre 1880 y 1898, y de nuevo desde 1906; y Panamá después de su separación de Colombia (1903) hasta 1916. Por otro lado, las normas sobre interpretación del Código de Bello fueron adoptadas, con diferente intensidad, en varios códigos americanos posteriores, aunque no haya ocurrido lo propio con el íntegro cuerpo legal chileno. Tal fue el caso de aquellos de Uruguay (1868), del segundo dado en Nicaragua (1904), del segundo promulgado en Honduras (1906) y del segundo promulgado en Panamá (1916).

Por consiguiente, la historia textual que acabamos de investigar interesa a muchos países del continente.

[Recibido el 1 y aprobado el 30 de julio de 2009].

\section{BIBLIOGRAFÍA}

Accursius, Glossa in Digestum Vetus, en Corpus Glossatorum Juris Civilis (Augustae Taurinorum, ex Officina Erasmiana, 1969), VII.

A Reprint of Moreau Lislet's Copy of a Digest of the Civil Laws now in Force in the

Territory of Orleans (1808) Containing Manuscript References to its Sources and

Other Civils Laws on the Same Subjects. The de la Vergne Volume (Baton Rouge, Louis. Claitor, 1971).

Augustinus, Principia rhetorices.

BATIZA, Rodolfo, Justinian's Institute and the Louisiana Civil Code of 1808, en Tulane Law Review 69 (junio de 1995) 6.

BATizA, Rodolfo, Origins of Modern Codification of the Civil Law: The French Experience and its Implications for Louisiana Law, en Tulane Law Review 56 (febrero de 1982) 2.

BATIZA, Rodolfo, Roman Law in the French and Louisiana Civil Codes: A Comparative Textual Survey, en Tulane Law Review 69 (1995) 6.

BatizA, Rodolfo, Sources of the Civil Code of 1808, Facts and Speculation: A Rejoinder, en Tulane Law Review 46 (abril de 1972) 4.

BatizA, Rodolfo, The Actual Sources of the Louisiana Project of 1823: A General Analytical Survey, en Tulane Law Review 47 (diciembre de 1972) 1.

BATIZA, Rodolfo, The Influence of Spanish Law in Louisiana, en Tulane Law Review 33 (diciembre de 1958) 1.

Batiza, Rodolfo, The Louisiana Civil Code of 1808: Its Actual Sources and Present Relevance, en Tulane Law Review 46 (septiembre de 1971) 1.

interpretación de las leyes (Santiago de Chile, LexisNexis [ahora LegalPublishing], 2006.- 2a edición, 2007), 258 págs. 
Baudouin, Louis, The Influence of the Code Napoleon, en Tulane Law Review 33 (diciembre de 1958) 1.

Blackstone, William, Commentaries on the Laws of England in four Books (8a edición, Oxford, Clarendon Press, 1778).

Caepolla, Bartholomaeus, De verborum et rerum significatione, en Opera (Lugduni, 1578).

CASTÁN VÁzQUez, José María, La influencia de la literatura jurídica española en las codificaciones americanas (Madrid, Real Academia de Jurisprudencia y Legislación, 1984).

Colvin, Milton, The Influence of the Ancient Laws of Spain on the Jurisprudence of Louisiana, en Tulane Law Review 6 (1931-1932).

Commentaires sur les loix angloises, de M. Blackstone. Traduits de l'Anglois par M. D. G sur la quatrième édition d'Oxford (Bruxelles, J. L. de Boubers, 1774-1776), seis volúmenes.

Commentaries on the Laws of England in four Books by Sir William Blackstone, Knt. [...]. The Thirteenth Edition, with the Last Corrections of the Autor, and with Notes and Additions by Edward Christian, Esq., Barrister at Law and Professor of the Laws on England in the University of Cambridge (London, Printed by S. Strahan for T. Cadell jun. and W. Davies, 1800), I.

Commentaries on the Laws of England in four Books by Sir William Blackstone, Knt. [...]. The Twelfth Edition, with the Last Corrections of the Autor, and with Notes and Additions by Edward Christian, Esq., Barrister at Law and Professor of the Laws on England in the University of Cambridge (London, Printed by S. Strahan \& W. Woodfall for T. Cadell, 1793-1795), 4 volúmenes.

DaINOW, Joseph, Moreau-Lislet's Notes on Sources of Louisiana Civil Code of 1808, en Lousiana Law Review 19 (1958).

DanneberG, Lutz, Logik und Hermeneutik im 17. Jahrhundert, en SCHRÖDER, Jan, Theorie der Interpretation vom Humanismus bis zur Romantik. Rechtswisenschaft, Philosophie, Theologie (Stuttgart, Steiner, 2001).

Darby, Lawrence - McDonald, Thomas, A Recent Discovery: Another Copy of Morean Lislet's Annotation to the Civil Code of 1808, en Tulane Law Review 47 (junio de 1973) 4.

DART, Henry, The Sources of the Civil Code of Louisiana: address delivered at the annual meeting of the Louisiana Bar Association, held at Lake Charles, La., Friday, June 2, 1911 (New Orleans, J. G. Hauser. 1911).

Digeste des lois civiles, en Compiled Edition of the Civil Code of Louisiana prepared by The Louisiana State Law Institute (Baton Rouge, Louisiana, 1940), III, 1.

DOMAT, Jean, Les lois civiles dans leur ordre naturel (Paris, chez Th. de Hansy, 1735), I.

Federicis, Stephanus de, De interpretatione legum, en Tractatus universi iuris (Venetiis, 1634).

Fenet, Pierre-Antoine, Recueil complet des travaux préparatoires du Code Civil (Paris, Videcoq, 1836), II.

FORSTER, Valentin Wilhelm, Interpres sive de interpretatione iuris libri duo (Witerbergae, Sumpt. C. Berger, Typis Meisnerianis, 1613).

Franklin, Mitchell, An Important Document in the History of American, Roman and Civil Law: The De la Vergne Manuscript, en Tulane Law Review 33 (diciembre de 1958) 1. 
Grotius, Hugo, De iure belli ac pacis libri tres (ed. B. J. A. De Kanter van Hettinga, Lugduni Batavorum, Brill, 1939, reimp. Aalen, Scientia, 1993)

GuZmán Brito, Alejandro, El "communis usus loquendi" en el Derecho romano, en Revista de Estudios Histórico-Jurídicos 21 (Valparaíso, 1999) = Bulletino dell'Istituto di Diritto Romano "Vittorio Scialoia", terza serie, 39 (1997 [pero 2004]).

GuZmán Brito, Alejandro, La reglas del Código Civil de Chile sobre interpretación de las leyes (Santiago de Chile, LexisNexis, 2006.- 2a edición, 2007), 258 págs.

GuZMÁN BRITO, Alejandro, Las normas sobre interpretación de las leyes contenidas en el "Projet de Code Civil" de l'an VIII (1800), en Labruna, Luigi (director), Cinquanta anni della Corte Costituzionale della Repubblica Italiana, I: Tradizione romanistica e costituzione (Napoli, Edizioni Scientifiche Italiane, 2006), I.

Hoffeimer, Michael, The Common Law of Edward Christian, en The Cambridge Law Journal 53 (Cambridge, UK., 1994).

Hood, John jr., Symposium: Louisiana and the Civil Law. A Crossroad in Louisiana History, en Louisiana Law Review 22 (1961-1962).

Hood, John jr., The History and Development of the Louisiana Civil Code, en Tulane Law Review 33 (diciembre de 1958) 1.

Hubert, León jr., Louisiane, en Travaux de la Semaine Internationale de Droit. L'influence du Code Civil dans le monde (Paris, Pedone, 1954).

Keckermann, Bartholomaeus, Systema Logicae (5a edición, Hanoviae, 1611).

Kilbourne, Richard H., A History of the Louisiana Civil Code: the Formative Years, 1803-1839 (Baton Rouge, Louisiana State University Press, 1987).

KnÜTel, Rolf, Influences of the Louisiana Civil Code in Latin America, en Tulane Law Review 70 (1996) 5.

Levasseur, Alain - Herman, Shael, Louisiane, en Travaux de l'Association Henri Capitant, XLIV: La circulation du modele juridique français (Paris, Litec, 1993).

Levasseur, Alain, Moreau Lislet: The Man Behind the Digest of 1808 (Baton Rouge, Claitor, 2088).

Lifsic, Ricardo, Historia del Código Civil de Louisiana antecedente del Código Civil Argentino, en Revista del Instituto de Historia del Derecho 12 (Buenos Aires, 1961).

Merrick, E. T., The Laws of Louisiana and their Sources, en The American Law Register 29 (enero de 1890) 1.

Pascal, Robert, A Recent Discovery: A Copy of the Digest of the Civil Laws of 1808 with Marginal Source Reference in Moreau Lislet's Hand, en Louisiana History 7 (1966).

PASCAL, Robert, Sources of the Digest of 1808: A Reply to Professor Batiza, en Tulane Law Review 46 (abril de 1972) 4.

PIANo-MortaRI, Vincenzo, Ricerche sulla teoria dell'interpretazione del Diritto nel secolo XVI, I: Le premesse (Milano, Giuffré, 1956).

Porter, B. F., Ancient Sources of Louisiana Law, en The Commercial Review of the South and West (New Orleans, 1846).

Pufendorf, Samuel, De iure naturae et gentium libri octo (Francofurti et Lipsiae, ex officina Knochio-Eslingeriana, 1759, reimpresión Frankfurt am Main, Minerva, 1967), I.

ReYnolds, C. Russell, Spanish Law Influence in Louisiana, en Hispania 56 (American Association of Teachers of Spanish and Portuguese, Walled Lake, Mi, diciembre de 1973) 4. 
SBRICCOLI, Mario, Linterpretazione dello statuto. Contributo allo studio della funzione dei giuristi nell'etá comunale (Milano, Giuffré, 1969), pp.174-190.

SNYDER, David, Ancient Law and modern Eyes, en Tulane Law Review 69 (junio de 1995) 6.

STONE, Ferdinand, The Civil Code of 1808 for the Territory of Orleans, en Tulane Law Review 33 (diciembre. 1958) 1.

SuÁrez, Francisco, De legibus ac Deo legislatore lib. VI, cap. 1º, núm. 9 (Conimbricae, Apud Didacum Gomez de Loureyro, 1612; reimpresión Madrid, Instituto de Estudios Políticos, 1967),IV.

SweEneY, Joseph, Tournament of Scholars over the Sources of the Civil Code of 1808, en Tulane Law Review 46 (abril de 1972) 4.

Tate, Thomas, A Digest of the Civil Laws Now in Force in the Territory of Orleans (1808), en Loyola Law Review 17 (1970-1971).

TuCKer, John, Source Books of Louisiana Law, en Tulane Law Review 6 (19311932).

TucKer, John, Source Books of Louisiana Law, en Tulane Law Review 6 (19311932).

Tucker, Thomas, Sources of Louisiana Law of Persons: Blackstone, Domat and the French Codes, en Tulane Law Review 44 (febrero de 1970) 2.

Tulus, Robert Lee, The Louisiana Civil Law in the Light of its Origin and Development, en University of Toronto Law Journal 2 (1937-1938).

Vogenauer, Stefan, Die Auslegung von Gesetzen in England und auf del Kontinent (Tübingen, Mohr Siebeck, 2001), I.

Wolf, Christian, Ius naturae método scientifica pertractatum pars sexta [Halae Magdebvrgicae, in Officina Libraria Rengeriana, 1746; reimpresión en Wolf, Christian, Gesammelte Werke, (Herausgegeben und Bearbeitet von L. École y otros, II. Abteilung: Lateinische Schriften, Band 22: Jus naturae, Herausgegeben und Bearbeitet por Marcel Thomann, Hildesheim, Georg Olms Verlagsbuchhandlung, 1968)]. 
